\title{
Acridine orange for diagnosis of malaria - Our experience
}

\author{
Neeta Jangale ${ }^{I}$, Ashwini Waghmare ${ }^{2}$ \\ ${ }^{1}$ Professor and Head, Department of Microbiology, Government Medical College Miraj, Maharashtra, India. ${ }^{2}$ Assistant \\ Professor, Department of Microbiology, MRMIS Hyderabad, Andhra Pradesh, India.
}

\begin{abstract}
Light microscopy of Romanowsky stained peripheral blood smear examination is the age old and commonest method for laboratory diagnosis of malaria. However it is labor intensive, time consuming and requires qualified personnel. So fluorescent microscopy variation that is Quantitative Buffy Coat method( $\mathrm{QBC}$ ) came into vogue. But QBC imposes cost limitation despite its high performance. Therefore we decided to evaluate fluorescent method using acridine orange in our set up. In this study we have compared Acridine Orange staining with Leishman's staining as gold standard. The sensitivity and specificity of acridine orange was $99.28 \%$ and $97.19 \%$ respectively, while positive predictive value (PPV) and negative predicitive value was $89.93 \%$ and $99.82 \%$ respectively.
\end{abstract}

Keywords: Acridine Orange, Fluorescent Microscopy, Leishman Staining, Malaria, Peripheral Smear.

\section{Introduction}

Malaria continues to be the major public health problem in India. At present, official figures for malaria in India, according to Directorate of National Vector Borne Disease Control Program (NVBDCP), Ministry of Health \& Family Welfare India, there were 11.26lac cases and 287 deaths in the year 2015 . $^{1}$ Malaria presents with such varied manifestations that in endemic areas like India, it has to be considered as differential diagnosis for almost all the cases presenting with fever. In view of the atypical presentations of malaria and mortality due to complications especially in falciparum malaria, timely diagnosis and accurate detection of infecting species is important.

The direct microscopic visualization of the malarial parasite on blood smears has been accepted method for diagnosis in most settings from clinical laboratories to field surveys; and light microscopy of Romanowsky`s stained peripheral blood smear examination remains the gold standard. The light microscopy has the advantages that it is sensitive, informative, relatively inexpensive, and provides permanent record and can be shared with other disease control programmes. However, it requires skilled and experienced personnel and it is labour intensive as well as time consuming. ${ }^{2}$

Our principle objective was to compare peripheral blood smear staining by acridine orange with Leishman staining as the gold standard for the diagnosis of malaria. We planned to evaluate acridine orange fluorescence technique with respect to staining quality and time needed for reporting.

\section{Materials and methods}

The present study was conducted over a period of one year on patients attending out-patient department of tertiary care teaching hospital. Patients of both sexes

\section{Practice Points}

- Malaria presents with varied manifestations in endemic areas, therefore should be considered as differential diagnosis for all the cases presenting with fever.

- Acridine orange staining can be used in centers with high load for reducing turnaround time.

- Acridine orange can be good even in smaller set ups like peripheral health centres where most of patients present with fever.

- Logistic problems need to be taken care of for performing fluorescent microscopy.

- Random positive samples by acridine orange staining should be further subjected to Romanowsky stain for performance comparison.

and all age groups presenting with acute febrile illness and clinically suspected of malaria, for whom malaria microscopy was requested formed the subjects; those on antimalarials were excluded from the study. Total 715 patients who gave informed consent were enrolled for the study.

Two millilitre venous blood was collected in EDTA bulb. Thin and thick blood films were prepared and subjected to Leishman staining procedure. ${ }^{2}$ Acridine orange wet mount was prepared as follows: ${ }^{3} 75 \mu \mathrm{l}$ of blood was taken on clean glass slide and $10 \mu \mathrm{l}$ of acridine orange stain was added to it with pipette. Mixture was covered with cover slip, cover slip pressed gently. The wet mount was examined under fluorescence microscope for two minutes; exciter filter : LP 450 and barrier filter: LP 520. ${ }^{4}$ The ring stage, trophozoites, and gametocytes appear pale apple green under the fluorescence microscope. ${ }^{5}$ Erythrocytes

Correspondence: Dr Neeta Jangale, 177, Rama Udyan Phase II, Pandharpur Road, Miraj 416410, India. Email: drneetaj@gmail.com.

South East Asia Journal of Public Health 2016;6(1):49-51. (c) 2016 Jangale \& Waghmare, publisher and licensee Public Health Foundation Bangladesh. This is an Open Access article which permits unrestricted non-commercial use, provided the original work is properly cited. 
being non-nucleated do not stain with acridine orange. 4

Statistical analysis was done by SPSS software version 16 demo and Microsoft Word, Excel have been used to generate tables, etc. Data was represented in the form of frequency and percentages. Diagnostic Statistics were used to calculate Sensitivity, Specificity, Positive Predictive and Negative Predictive Value.

\section{Results}

Of total 715 patients, 159 cases were positive by Leishman staining method which was taken as gold standard and $144(20.14 \%)$ by acridine orange (Table 1).

Out of 159 cases positive by Leishman stain, $80.50 \%$ were $P$. vivax, $15.09 \%$ were $P$. falciparum, and remaining $4.41 \%$ were mixed infection. Correspondingly amongst 144 cases positive by acridine orange, $81.26 \%$ were $P$. vivax and $15.27 \%$ were $P$. falciparum and $3.47 \%$ were with mixed infection (Table 2).

The sensitivity of acridine orange was $99.28 \%$ and specificity was $97.19 \%$ with respect to Leishman stain, while positive predictive value (PPV) and negative predicitive value was $89.93 \%$ and $99.82 \%$ respectively.

\section{Discussion}

Rapid and accurate detection of malaria parasite with subsequent effective treatment is a prerequisite in reducing the morbidity and mortality due to the disease. Microscopic examination of peripheral blood smear is still considered standard method of malaria diagnosis.

The commonly employed method for the diagnosis of malaria involves the microscopic examination of Romanowsky stained blood films. Although a peripheral blood smear allows identification of Plasmodial species and stages, the technique is labourious, time consuming, employs multiple reagents and steps delaying the reports. Blood smears may not be processed immediately but processed in batches further delaying the report. All the more it requires well trained microscopist for accurate identification. To overcome these limitations staining with fluorescent dyes has been developed and many workers have evaluated acridine orange for malaria diagnosis., ${ }^{2,-6}$

We compared performance of acridine orange with Leishman stain as a gold standard. $20.14 \%$ cases were identified as malaria positive by acridine orange against $22.24 \%$ by Leishman stain (Table 1 ) and our findings are in conformity with the results of Mendiratta et al. ${ }^{3}$ study $(18.28 \%)$. Hemvani et $a .^{4}$ found acridine orange to be better than Leishman stain.

In present study acridine orange identified $15.27 \%$ as falciparum malaria cases and $81.25 \%$ as vivax cases and missed two cases of falciparum malaria, eleven cases of vivax malaria and two cases of mixed infection (Table 2).

Various studies on acridine orange reported sensitivity and specificity ranging from $77-100 \%$ and $80-100 \%$ respectively. ${ }^{3,5-7}$ In the present study, sensitivity and specificity was well above $90 \%$ i.e., $99.28 \%$ and $97.19 \%$ respectively. Sensitivity of acridine orange in our study correlated well with that reported by Mendiratta et $a l^{3}{ }^{3}$, Keiser et $a l^{6}{ }^{6}$, and Lowe et $a l^{7}$ Sixteen positive samples were missed by acridine orange and the positive predictive value was found to be $89.93 \%$ where as negative predictive value was $99.82 \%$.

Reviewed Indian and foreign literature validates that the acridine orange method shows good diagnostic performance and promptness. ${ }^{3-5}$ Some workers have found $100 \%$ correlation between Leishman stain and acridine orange stain. ${ }^{3}$ While some have found acridine orange to be better than Leishman stain. The experience of various studies also emphasized the rapidity of acridine orange method and results were available within 2 minutes. ${ }^{4} \mathrm{We}$ also found that acri-

Table 1: Comparison of percentage positivity

\begin{tabular}{|c|c|c|c|}
\hline \multirow{2}{*}{\multicolumn{2}{|c|}{ Leishman Stain }} & \multicolumn{2}{|c|}{ Acridine Orange Stain } \\
\hline & & Positive & Negative \\
\hline Positive & $159(22.24 \%)$ & $143(89.94 \%)$ & $16(10.06 \%)$ \\
\hline Negative & $556(77.76 \%)$ & $1(0.18 \%)$ & $555(99.82 \%)$ \\
\hline Total & $715(100 \%)$ & $144(20.14 \%)$ & $571(79.86 \%)$ \\
\hline
\end{tabular}

Table 2: Distribution of parasite species in positive cases by two methods

\begin{tabular}{|c|c|c|c|}
\hline \multicolumn{2}{|c|}{ Diagnostic Method } & Count & Percentage \\
\hline \multirow{4}{*}{ Leishman Stain } & PF & 24 & $15.09 \%$ \\
\cline { 2 - 4 } & PV & 128 & $80.5 \%$ \\
\cline { 2 - 4 } & Mixed & 7 & $4.41 \%$ \\
\cline { 2 - 4 } & Total & 159 & $100 \%$ \\
\hline \multirow{3}{*}{ Acridine Orange Stain } & PF & 22 & $15.27 \%$ \\
\cline { 2 - 4 } & PV & 117 & $81.26 \%$ \\
\cline { 2 - 4 } & Mixed & 5 & $3.47 \%$ \\
\cline { 2 - 4 } & Total & 144 & $100 \%$ \\
\hline
\end{tabular}

PF: P. falciparum; PV: P. vivax. 
dine orange stain correlated well with traditional Leishman stain and it has the advantage of faster screening, results being available within 2-10 minutes. However, the drawback is acridine orange stained wet mounts cannot be preserved, unlike the Leishman stained smear.

Though it was speedy and rapid method we experienced that the light was too uncomfortable, clumping of leucocytes obscuring the parasite and difficulty in trophozoite identification lead to improper detection of parasites. Acridine orange stain method was not as sensitive as Leishman staining method when parasitemia was $<1 \%$. Overall, acridine orange staining in the form of wet mount offers simple, rapid and efficient procedure for detection of malaria parasite, but currently fluorescent microscopes are used in very few laboratories especially in teaching hospitals and reference or research centres.

\section{Conclusion}

Thus to conclude, acridine orange staining may be used in centres with high load for faster screening of peripheral blood samples. High cost may be an initial barrier for availability in smaller set-ups and if the logistic problems are taken care of acridine orange can prove good even in smaller set ups like peripheral health centres.

\section{Competing interest}

The authors declare that they have no competing interests.

\section{References}

1. National Vector Borne Disease Control Programme. (NVBDCP). Malaria situation in India. http://nvbdcp.gov.in/malaria-new.html (accessed June 2016)
2. Chatterjee KD. Parasitology in relation to clinical medicine. 12th ed. Calcutta: Chatterjee Medical Publisher, 1995.

3. Mendiratta DK, Bhutada K, Narang R, Narang P. Evaluation of different methods for diagnosis of P. Falciparum malaria. Indian J Med Microbiol 2006;24(1):49-51.

4. Hemvani N, Chitnis DS, Dixit DS, Asolkar MV. Acridine orange stained blood wet mounts for fluorescent detection of malaria. Indian J Pathol Microbiol 1999;43(1):12528.

5. Lema OE, Carter JY, Nagelkerke N, Wangai MW, Gikunda SM, Arube PA, et al. Comparison of five methods of malaria detection in the outpatient setting. Am J Trop Med Hyg 1999;60(2):177-82.

6. Keiser J, Utzinger J, Premji Z, Yamagata $\mathrm{Y}$, Singer BH. Acridine Orange for malaria diagnosis: its diagnostic performance, its promotion and implementation in Tanzania, and the implications for malaria control. Ann Trop Med Parasitol 2002;96 (7):643-54.

7. Lowe BS, Jeffa NK, New L, Pedersen C, Engback K, Marsh K. Acridine orange fluorescence technique as alternatives to traditional Giemsa staining for the diagnosis of malaria in developing countries. Trans $R$ Soc Trop Med Hyg 1996;90:34-6. 